\title{
Algorithm for the diagnosis of patients with neurodevelopmental disorders and suspicion of a genetic syndrome
}

\author{
Luis A. Méndez-Rosado, PhD. ${ }^{a}$, Damaris García, M.D. ${ }^{a}$, Odalis Molina-Gamboa, B.S. ${ }^{a}$, Alina García, M.D. ${ }^{b}$, \\ Norma de León, M.D. ${ }^{b}$, Araceli Lantigua-Cruz, M.D. ${ }^{a}$ and Thomas Liehr, M.D. ${ }^{c}$
}

\begin{abstract}
The wide range of chromosome aberrations seen in neurodevelopmental disorders may not always be characterized by means of a chromosome analysis. The objective of this study was to determine the genetic etiology of these disorders in patients with congenital neurological conditions and clinical suspicion of a genetic disorder using a clinical and molecular testing algorithm. Among 111 studied children, 71 showed submicroscopic chromosome aberrations associated with microdeletion/microduplication syndromes: DiGeorge (22 cases), Prader-Willi (26 cases), Angelman (2 cases), WilliamsBeuren (17 cases), Smith-Magenis (1 case), Miller-Dieker (1 case), and cri $d u$ chat syndrome (1 case). Additionally, a de novo trisomy $17 \mathrm{p} 12 \mathrm{p} 11.2$ due to an unbalanced insertion into 5 p13.1 was identified in a 3-year-old child. In most cases, the use of a clinical method together with molecular techniques, such as fluorescence in situ hybridization, has allowed to make an accurate diagnosis in patients and/or families with neurodevelopmental disorders.

Key words: neurodevelopmental disorders, microdeletion/ microduplication syndrome, FISH, clinical pathways.
\end{abstract}

http:/ / dx.doi.org/10.5546/ aap.2020.eng.52

To cite: Méndez-Rosado LA, García D, Molina-Gamboa O, García A, et al. Algorithm for the diagnosis of patients with neurodevelopmental disorders and suspicion of a genetic syndrome. Arch Argent Pediatr 2020;118(1):52-56. a. National Center of Medical Genetics, Havana, Cuba.

b. Hospital Pediátrico "William Soler," Havana, Cuba.

c. Jena University Hospital, Friedrich Schiller University, Institute of Human Genetics, Jena, Germany.

E-mail address:

Luis A. Méndez-Rosado, PhD: albermen@infomed.sld.cu

Funding: None.

Conflict of interest: None.

Received: 1-11-2019

Accepted: 8-2-2019

\section{INTRODUCTION}

Neurodevelopmental disorders (NDD) are defined as the delayed development of motor function, cognitive skills or language or combined deficits in these areas before 5 years of age. ${ }^{1}$ It has been estimated that genetic causes account for half of all cases ${ }^{2}$ and that chromosome aberrations (CA) due to submicroscopic rearrangements represent $5-10 \%$ in this group. ${ }^{3}$ However, causative factors are greatly heterogeneous, which hinders the possibility of establishing an etiologic diagnosis, which is only possible in $50-70 \%$ of all cases, whereas the rest are considered non-specific. Notwithstanding this, a study has reported that only $19.9 \%$ of patients receive a specific genetic diagnosis. ${ }^{4,5}$

Molecular cytogenetic techniques have been implemented in Cuba since 2009 and they have become an invaluable tool for the etiologic diagnosis of NDD, with the detection of rearrangements smaller than 5-10 Mb in patients without a definite prior diagnosis. In our setting, the conditions studied by fluorescence in situ hybridization (FISH) include syndromes caused by genomic imbalances at the chromosome level, such as deletions, duplications, and other rearrangements.

In addition, high-resolution (HR) chromosome techniques have enabled, through chromosome elongation, the detection of cryptic aberrations in unexpected genome locations. The phenotypic impact of CA is usually associated with the type, origin, and size of the aberration, the role of genes involved, and the interaction with other genetic and environmental modulating factors. The common thread that runs through clinical manifestations is NDD of varying severity, together with weight deficit, dysmorphisms and / or major birth defects.

\section{OBJECTIVE}

To determine the genetic etiology of NDD in patients with congenital neurological conditions and clinical suspicion of a genetic disorder using a clinical and molecular testing algorithm. 


\section{METHODS}

Design: This was a retrospective, cross-sectional study in 120 patients referred to the National Center of Medical Genetics of Havana and conducted by clinical geneticists in the 2010-2017 period. Given the clinical characteristics of patients, they were suspected of microdeletion/microduplication syndrome (MMS).

\section{Cytogenetic analysis}

Peripheral blood culture samples were used to obtain HR chromosome preparations (> 550 bands) based on the standard protocols described in The AGT Cytogenetics Laboratory Manual. ${ }^{6}$

\section{Molecular cytogenetics}

FISH tests were done using probes (Abbott/ Vysis, USA) depending on the patient's clinical characteristics that led to suspicion of a specific MMS. In an additional case, a more complex FISH test was done to characterize a derivative chromosome $5 .^{7}$

\section{Ethical considerations}

Parents or legal guardians signed an informed consent for the study of these patients. The Ethics Committee of the National Center of Medical Genetics approved this study.

\section{RESULTS}

In total, $95 \%$ of study patients were younger than 13 years old (111 cases). Table 1 shows a summary of the results found in 111 patients with NDD. The submicroscopic aberration causing the NDD was identified in 71 of the 111 studied patients.

The following CA were detected: DiGeorge (22 cases), Prader-Willi (26 cases), Angelman ( 2 cases), Williams-Beuren (17 cases), SmithMagenis (1 case), Miller-Dieker (1 case), and cri $d u$ chat syndrome (1 case). Additionally, a de novo trisomy $17 \mathrm{p} 12 \mathrm{p} 11.2$ due to an unbalanced insertion into 5p13.1 was identified in a 3-year-old child after the HR chromosome analysis revealed a derivative chromosome 5 .

\section{DISCUSSION}

In high-income countries, array-based comparative genomic hybridization (aCGH) is the first-line tool for the diagnosis of patients with NDD. Other less expensive techniques include multiplex ligation-dependent probe amplification and may also be useful for the diagnosis of
MMS. In countries like Cuba, this technology is not available; for this reason, clinical diagnosis, including an interview with patients and/or their parents or legal guardians, plays a critical role as part of the path towards an accurate diagnosis. In addition, the use of HR chromosome techniques together with GTG banding and FISH provide complementary results for patient clinical analysis and allow to develop an algorithm for the diagnosis of our patients with NDD (Figure 1).

In the case series described in this article, the implementation of this algorithm led to the accurate diagnosis of $64 \%$ of patients based mainly on a correct clinical characterization. However, this is sometimes difficult because a specific syndrome may display a greatly variable phenotype. For example, in our series, heart diseases were observed in $87 \%$ of DiGeorge syndrome patients, specifically ventricular septal defect, patent truncus arteriosus, and tetralogy of Fallot. Similar results have been reported in the bibliography, with $31-80 \%$ of cases showing heart diseases. ${ }^{8,9}$

The second most common clinical manifestation observed in our patients were facial dysmorphisms. According to the bibliography, the distinctive facies in DiGeorge syndrome includes long face, flattened malar region, narrow palpebral fissure, ptosis, tubular nose. In our series, facial dysmorphisms were observed in $78 \%$ of patients. In addition, thymus hypoplasia and / or immune deficiency were reported in $64 \%$ of patients. Intellectual disability was observed only in $50 \%$ of our patients. In general, this is consistent with what has been reported in the bibliography. ${ }^{8,9}$ However, some patients with DiGeorge syndrome may have small, atypical 22q11.2 deletions that may only be detected using aCGH. ${ }^{10,11}$

Clinical analysis may also be more complex in the case of Prader-Willi syndrome; actually, in our patients, it was confirmed in only $50 \%$ of suspected cases. Since $70 \%$ of these cases were caused by a deletion in the 15q11-q13 region, two situations are suggested: 1 . Some of our patients without confirmation had a maternal uniparental disomy as the cause of the syndrome and was not recognized using the FISH technique. 2. Probably, some of these patients had a condition other than Prader-Willi syndrome, such as uniparental disomy of chromosome $14,{ }^{12} 12 q$ subtelomere deletions, ${ }^{13}$ or Xq27-qter disomy. ${ }^{14}$ These events cannot be detected by HR chromosome or FISH techniques when the probe 
of the critical 15q11-q13 region is used. It is also correct to note that the critical region of PraderWilli may have distal, atypical deletions ${ }^{15}$ which cannot be detected with the probes used here.

We believe that the algorithm proposed in this study was valid in spite of the study limitations, which failed to make an accurate diagnosis in $26 \%$ of our patients due to the unavailability of the adequate technology. The algorithm helped to diagnose, in most cases, the genetic cause that had led to the NDD and also facilitated the possibility of offering good-quality genetic counseling and relevant information for their future descendants.

\section{CONCLUSIONS}

The use of the proposed working algorithm helped to make an accurate diagnosis of patients and/or families with NDD and clinical suspicion of a genetic disorder.

\section{REFERENCES}

1. Battaglia A, Bianchini E, Carey JC. Diagnostic yield of the comprehensive assessment of developmental delay/mental retardation in an institute of child neuropsychiatry. Am J Med Genet. 1999; 82(1):60-6.

2. SureshP, Ayyappan A, NandiniJ, Ismail T. Cognitive deficits and behavioral disorders in children: A comprehensive multidisciplinary approach to management. Ann Behav Sci. 2015; 1(1):6.

TABLE 1. Clinical suspicion, applied probes, number of studied cases, positive cases, and clinical characteristics of patients

\begin{tabular}{|c|c|c|c|c|}
\hline Clinical suspicion & FISH probes & Cases & $\begin{array}{l}\text { Positive } \\
\text { cases }(\%)\end{array}$ & $\begin{array}{c}\text { Associated clinical } \\
\text { characteristics }\end{array}$ \\
\hline $\begin{array}{l}\text { Velo-cardio-facial } \\
\text { syndrome }\end{array}$ & $\begin{array}{l}\text { LSI TUPLE1 / ARSA } \\
\text { LSI NP-25/ ARSA }\end{array}$ & 31 & $\begin{array}{l}22(71) \\
\text { (2 cases were inherited } \\
\text { from the mother, } \\
\text { prenatally) }\end{array}$ & $\begin{array}{l}\text { Congenital heart diseases, palate defects, } \\
\text { immune deficiency, NDD. }\end{array}$ \\
\hline $\begin{array}{l}\text { Williams-Beuren } \\
\text { syndrome }\end{array}$ & LSI ELN/D7S486, D7S522 & 18 & $17(94)$ & $\begin{array}{l}\text { Elfin facies, congenital heart disease and } \\
\text { delayed psychomotor development, } \\
\text { visual-spatial involvement. }\end{array}$ \\
\hline $\begin{array}{l}\text { Prader-Willi } \\
\text { syndrome }\end{array}$ & $\begin{array}{l}\text { P15 (D15Z1)/LSI SRNPN/ } \\
\text { PML CEP15 (D15Z1)/ } \\
\text { LSI D15S10/PML }\end{array}$ & 52 & $26(50)$ & $\begin{array}{l}\text { Hypotonia, hyperphagia, hypogonadism, } \\
\text { mental retardation, short stature. }\end{array}$ \\
\hline Angelman syndrome & & 3 & $2(67)$ & $\begin{array}{l}\text { Delayed psychomotor development, } \\
\text { paroxysmal bursts of laughter, ataxia, } \\
\text { puppet-like movements of the arms, } \\
\text { seizures. }\end{array}$ \\
\hline $\begin{array}{l}\text { Smith-Magenis } \\
\text { syndrome }\end{array}$ & LSI SMS / RARA & 3 & $1(33)$ & $\begin{array}{l}\text { Failure to thrive, brachydactyly, } \\
\text { brachycephaly, hypotonia, mental } \\
\text { retardation, self-harming behavior, } \\
\text { short flat head, prominent forehead. }\end{array}$ \\
\hline $\begin{array}{l}\text { Miller-Dieker } \\
\text { syndrome }\end{array}$ & LSI LIS1 / RARA & 2 & $1(50)$ & $\begin{array}{l}\text { Agenesis or hypoplasia of the corpus } \\
\text { callosum, severe mental impairment with } \\
\text { hypotonia, seizures, spasticity, } \\
\text { failure to thrive. }\end{array}$ \\
\hline $\begin{array}{l}\text { Cri du chat } \\
\text { syndrome }\end{array}$ & $\begin{array}{c}\text { LSI } \\
\text { D5S23,D5S721/EGR1 }\end{array}$ & 1 & $1(100)$ & $\begin{array}{l}\text { Low birth weight, delayed growth, cry } \\
\text { that sounds like that of a cat, } \\
\text { mental retardation, hypotonia, } \\
\text { hypertelorism, microcephalus. }\end{array}$ \\
\hline $\begin{array}{l}\text { Non-specific } \\
\text { clinical } \\
\text { characteristics* }\end{array}$ & $\begin{array}{l}\text { Microdissection } \\
\text { technique } \\
\text { described in } 7\end{array}$ & 1 & $1(100)$ & $\begin{array}{l}\text { Delayed psychomotor development } \\
\text { and dysmorphic signs. }\end{array}$ \\
\hline Total & & 111 & $71(64)$ & \\
\hline
\end{tabular}

* Patient in whom a derivative chromosome 5 was found through HR chromosome analysis.

FISH: fluorescence in situ hybridization; NDD: neurodevelopmental disorder. 


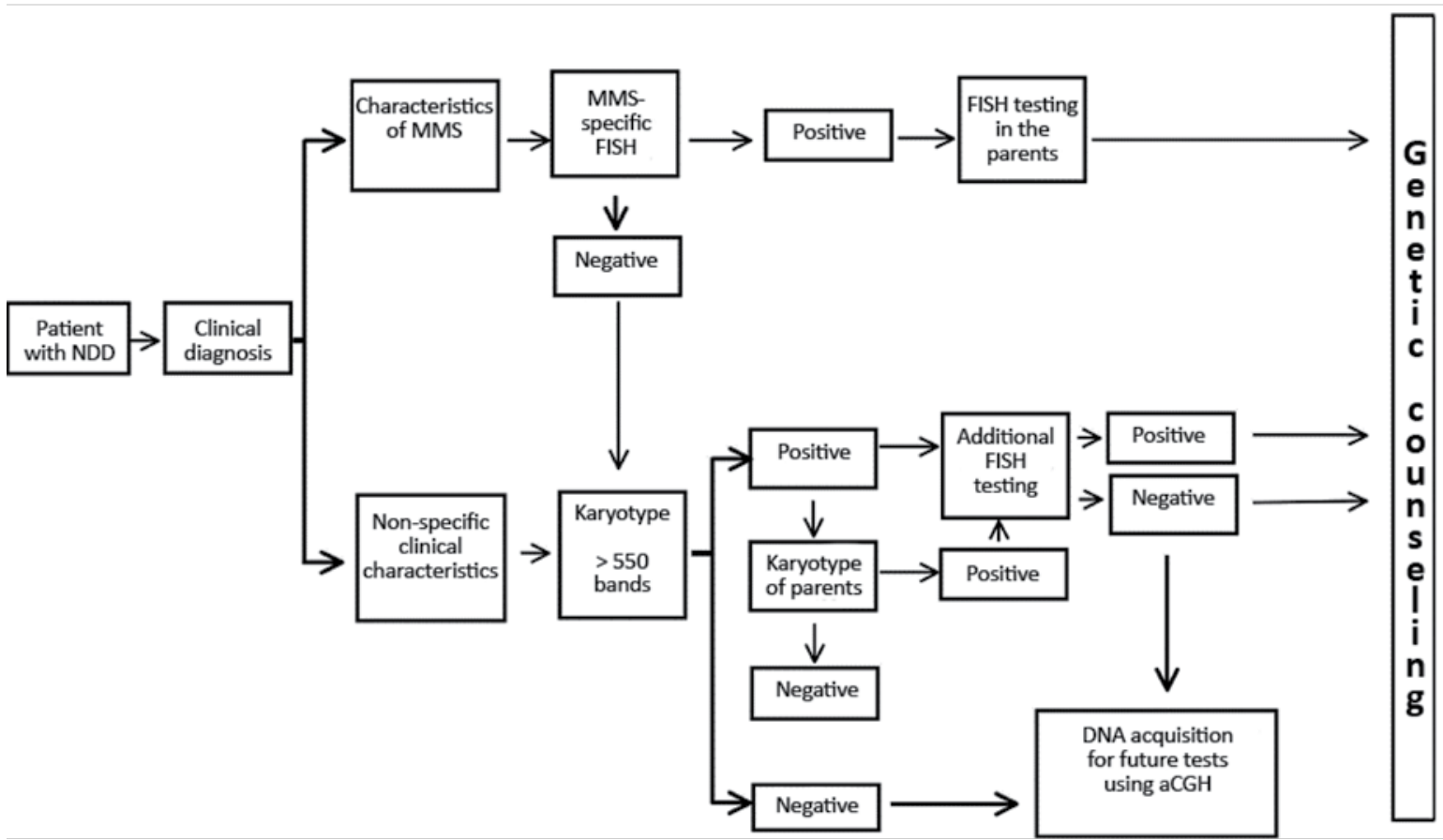

NDD: neurodevelopmental disorder; MMS: microdeletion/microduplication syndrome; aCGH: microarray technique; DNA: deoxyribonucleic acid; FISH: fluorescence in situ hybridization.

3. Patel DR, Merrick J. Neurodevelopmental disabilities: Introduction and epidemiology. In Patel R, Greydanus D, Omar H, Merrick J. Neurodevelopmental Disabilities. New York: Springer; 2011.Pages1-13.

4. Shevell M, Ashwal S, Donley D, Flint J, et al. Practice parameter:evaluation of thechild with globaldevelopmental delay: report of the Quality Standards Subcommittee of the American Academy of Neurology and The Practice Committee of the Child Neurology Society. Neurology. 2003; 60(3):367-80.

5. Johnston TD, Edwards L. Genes, interactions and the development of behavior. Psychol Rev. 2002; 109(1):26-34.

6. Barch MJ. AGT Cytogenetics Laboratory Manual. $2^{\text {nd }} e d$. New York: Raven Press; 1991.

7. Mendez-Rosado LA, Lantigua A, Galarza J, Al-Rikabi ABH, et al. Unusual de novo partial trisomy 17p12p11.2 due to unbalanced insertion into $5 \mathrm{p} 13.1$ in a severely affected boy. J Pediatr Genet. 2017; 6(3):165-8.

8. Cancrini C, Puliafito P, Digilio MC, Soresina A, etal. Clinical features and follow-up in patients with 22q11.2 deletion syndrome. J Pediatr. 2014; 164(6):1475-80.

9. Poirsier C, Besseau-Ayasse J, Schluth-Bolard C, Toutain J, et al. A French multicenter study of over 700 patients with 22q11 deletions diagnosed using FISH or aCGH. Eur J Med Genet. 2016; 24(6):844-51.
10. Verhagen J, Diderich K, Oudesluijs G, Mancini G, et at. Phenotypic variability of atypical $22 \mathrm{q} 11.2$ deletions not including TBX1. Am J Med Genet A. 2012;158A(10):2412-20.

11. Fernández L, Nevado J, Santos F, Heine-Suner D, et al. A deletion and a duplication in distal 22q11.2 deletion syndrome region. Clinical implications and review. BMC Med Genet. 2009; 10:48.

12. Hosoki K, Kagami M, Tanaka T, Kubota M, et al. Maternal uniparental disomy 14 syndrome demonstrates PraderWilli syndrome-like phenotype. J Pediatr. 2009; 155(6):9003.e1.

13. Niyazov DM, Nawaz Z, Justice AN, Toriello HV, et al. Genotype/phenotype correlations in two patients with 12q subtelomere deletions. Am J Med Genet A. 2007; $143 \mathrm{~A}(22): 2700-5$

14. Ben-Abdallah-Bouhjar I, Hannachi H, Labalme A, Gmidene A, et al. Chromosomal microarray analysis of functional Xq27-qter disomy and deletion 3p26.3 in a boy with PraderWilli like features and hypotonia. Eur J Med Genet. 2012; 55(8-9):461-5.

15. Calounova G, Hedvicakova P, Silhanova E, Kreckova $\mathrm{G}$, et al. Molecular and clinical characterization of two patients with Prader-Willi syndrome and atypical deletions of proximal chromosome 15q. Am J Med Genet A. 2008; 146A(15):1955-62. 